\title{
Características morfométricas do desenvolvimento do timo em cães ${ }^{1}$
}

\author{
Fernanda R. Agreste ${ }^{2}$, Pedro P. Bombonato ${ }^{3 *}$ e Francisco J. Hernandez-Blazquez ${ }^{3}$
}

\begin{abstract}
Agreste F.R., Bombonato P.P. \& Hernandez-Blazquez, F.J. 2007. [Morphometric characteristics of thymus development in dogs.] Características morfométricas do desenvolvimento do timo em cães. Pesquisa Veterinária Brasileira 27(6):236-240. Departamento de Cirurgia, Setor de Anatomia dos Animais Domésticos e Silvestres, Universidade de São Paulo, Avenida Prof. Dr. Orlando Marques de Paiva 87, São Paulo, SP 05508-000, Brazil. E-mail: bombonat@usp.br

The thymus is an organ with great immunological relevance during foetus life and neonatal period, It is the predecessor of lymphopoiesis and shows high lymphopoietic activity, being also the largest lymphoid organ during intrauterine life and at birth. In this study, the morphological aspects of the prenatal development of dog thymus were described in foetus of different ages and sexes. Twenty-four foetus of mongrel domestic dogs, males and females, were divided into four age groups. The thymus presented two lobes linked by a rose-colored tissue connection that was localized in the cranial mediastinal space. The cranial portion protrudes slightly beyond the first pair of ribs. The cells that formed the thymus parenchyma were well organized. Concentric aggregates named Hassal corpuscles were observed, involved by a thin capsule of connective tissue thickened by adipose tissue. The vessels size gradually increased with the foetus age, being larger in animals that were closer to birth. The volume (Vref) and size parameters of female thymus were larger than in males.
\end{abstract}

INDEX TERMS: Thymus, vascularization, lymphatic system, morphometry, dogs.

RESUMO.- O timo é um órgão de grande importância imunológica durante a vida fetal e o período neonatal. Ele é o precursor da linfopoiese e apresenta alta atividade linfopoiética, sendo também o maior órgão linfóide durante a vida intrauterina e até o nascimento. Neste estudo, os aspectoso morfológicos do desenvolvimento prenatal de timos de cães foram descritos em fetos de diferentes idades e sexos. Vinte e quatro fetos de cães domésticos, sem raça definida, machos e fêmeas, foram divididos em 4 grupos etários. 0 timo apresentou-se composto por dois lobos unidos por um tecido de conexão, com coloração rósea, localizados no espaço mediastinal cranial. A porção cranial estendeuse pouco além do primeiro par de costelas. As células que formavam o parênquima do timo estavam bem organizadas. Agrega-

\footnotetext{
${ }^{1}$ Recebido em 31 de março de 2007. Aceito para publicação em 8 de junho de 2007.

2 Pós-Graduanda do Departamento de Cirurgia, Faculdade de Medicina Veterinária e Zootecnia (FMVZ), Universidade de São Paulo (USP), Av. Prof. Dr. Orlando Marques de Paiva 87, Cidade Universitária, São Paulo, SP 05508000, Brasil.

${ }^{3}$ Departamento de Cirurgia , FMVZ-USP. Autor para correspondência: bombonat@usp.br
}

dos concêntricos chamados Corpúsculos de Hassal foram observados, envolvidos por uma delgada cápsula de tecido conjuntivo que é espessada por tecido adiposo. O tamanho dos vasos aumentou gradativamente com a idade dos fetos, sendo maior nos animais próximos ao nascimento. Os timos das fêmeas apresentaram maior volume (Vref) e dimensões de tamanho que nos machos.

TERMOS DE INDEXAÇÃO: Timo, vascularização, sistema linfático, morfometria, cães.

\section{INTRODUÇÃO}

Diante dos constantes avanços da ciência na área da imunologia e da indubitável importância que esta área vem adquirindo atualmente, faz-se cada vez mais necessário o empreendimento de estudos que visem conhecer aspectos diversos concernentes ao sistema imunitário, buscando a elucidação de doenças e seus tratamentos, tendo como principal enfoque os estudos relativos aos diferentes mecanismos de aquisição de defesas orgânicas, particularmente aquelas decorrentes dos esquemas de vacinação propostos classicamente para as distintas espécies animais. 
É de conhecimento da ciência que diversas reações imunológicas são exaradas após exposição de antígenos, sendo assim, a imunidade corporal está associada com atividades relacionadas aos órgãos linfomielóides e células, sendo o sistema linfático constituído de uma rede de defesa difusa e distribuída estrategicamente, seja na forma de folículos dispersos ou agregados, contra organismos infecciosos e outros materiais nocivos (Seto 1981).

Diversos experimentos têm revelado que no desenvolvimento normal, a manutenção dessas estruturas linfóides é dependente de um órgão linfóide específico quanto ao caráter precursor linfopoiético - o timo. Assim como, as respostas imunológicas naturais ou induzidas que estão de diferentes formas relacionadas às estruturas do sistema linfático, muitas vezes são intermediadas e coordenadas pelo timo (Appolinário 1998, Bombonato 1997).

Apesar de a função tímica ser responsabilizada por mecanismos fundamentais na aquisição das defesas e conseqüientes respostas orgânicas, ela ainda não é totalmente esclarecida, tampouco as bases morfológicas que respondem por tais funções, assim como seu processo de desenvolvimento e involução, constituição estrutural, ainda estão por serem respondidas (Bombonato 1997).

Ainda na vida fetal e no período neonatal o timo é o órgão com maior importância imunológica e, anatomicamente é o maior órgão linfático com maior atividade linfopoética, constando como precursor da linfopoese, demonstrando também relações com o sistema endócrino, principalmente com a função gonadal (Drummond 1996).

Estudos confirmam a importância do timo no desenvolvimento e manutenção do sistema imunológico e endócrino, particularmente no que tange as gônadas, na qual tornam-se comprometidas em animais recém-nascidos submetidos à timectomia (Appolinário 1998, Machado 1989).

O significativo papel do timo na imunidade é demonstrado em algumas espécies pela timectomia neonatal. Isso causa o enfraquecimento da reação de hipersensibilidade retardada. A habilidade para produzir respostas mediadas por anticorpos também fica prejudicada, uma vez que a produção de anticorpos requer a colaboração das células T (Banks 1991).

No que diz respeito à irrigação do timo em cães, em particular, no respeitante aos seus aspectos quantitativos, a literatura é escassa, visto que os autores quando se reportam ao assunto fazem-no de maneira genérica. Já os especialistas que trabalharam com a irrigação do timo, de forma geral, somente fazem menção aos grandes e pequenos ruminantes, e ainda assim descrevendo tão somente os vasos responsáveis pela nutrição do órgão.

O conhecimento do comportamento vascular, de sua estrutura, das interferências que ocorrem no desenvolvimento e na involução do timo, bem como os reflexos que tais eventos determinam sobre a marcação imunológica dos animais pode esclarecer diversas entidades ainda não caracterizadas adequadamente como doenças auto-imunes, tumores tímicos, persistência tímica e outras ligadas ao comprometimento imunitário, auxiliando assim, na clínica veterinária.
Diante desses aspectos, objetivamos estudar os aspectos morfológicos como o tamanho e volume do timo, e aspectos histológicos da vascularização do timo em cães, correlacionando com o sexo e o desenvolvimento etário.

\section{MATERIAL E MÉTODOS}

Para a realização desta pesquisa foram coletados 24 timos provenientes de fetos e recém-natos de cães domésticos (Canis familiaris), sem raça definida (SRD), machos e fêmeas em igual número, com 30 , 4050 e 60 dias, separados em 4 grupos etários (doravante designados de Grupo I, II, III, IV, respectivamente), não apresentando nenhum grau de consangüinidade. A lavagem do sistema circulatório do timo foi realizada por meio de perfusão com solução contendo solução salina tamponada fosfatada (PBS) e heparina a $2 \%$, em seguida, a solução fixadora de Karnovsky modificada. Os timos foram removidos e mensurados em seu eixo longitudinal e transversal (tanto na região cranial e caudal), orientando o sentido crânio-caudal do mesmo, assim, obtivemos as medias de comprimento, espessura e largura do órgão. Em seguida, foram seccionados transversalmente originando planos macroscópicos paralelos e seriados, com distância média de $3 \mathrm{~mm}$ como descritos no trabalho de Mayhew (1992) e Wulfsohn et al. (2004). O volume do órgão ou volume referência (V(ref)) foi estimado pelo método de Cavalieri (Gundersen \& Jensen 1987, Mayhew 1992). As fatias escolhidas aleatoriamente obedeceram ao método orientator modificado (Mattfeldt et al. 1990), assim obtivemos cortes AUI (Aleatórios e Uniformemente Isotrópicos) ou IUR (Isotropic Uniform Random). Após permaneceram imersos no fixador por um período mínimo de 24 horas. Posteriormente, os fragmentos foram processados, cortado em cortes semi-finos com $1 \mu \mathrm{m}$ de espessura, e corados com azul de toluidina, para posterior análise histológica dos cortes.

Para a análise estatística foram utilizados os testes não-paramétricos de Mann-Whitney e Wilcoxon, com nível de significância de $5 \%$.

\section{RESULTADOS}

Nos cães dos diferentes grupos etários analisados, macroscopicamente, os timos apresentavam coloração rósea, localizados no espaço mediastinal cranial, entre os pulmões e acima da base do coração. Na porção cranial apresentavam discreta divisão entre o lobo esquerdo e direito, sendo unidos por um tecido de conexão. Na porção caudal os lobos direito e esquerdo eram totalmente separados, sendo o lobo direito maior que o esquerdo. Sua porção cranial estendia-se pouco além do primeiro par de costelas, e sua porção caudal próximo ao quinto par de cartilagens costais.

Apresentavam suprimento sanguiíneo pelas artérias torácica interna direita e esquerda, estas penetravam no parênquima de cada lobo tímico, ramos tímicos do tronco braquiocefálico, artérias subclávia direita e esquerda, tronco costocervical, primeira intercostal e artéria pericardicofrênica.

De forma geral, o comprimento, a espessura e a largura do timo tiveram um aumento gradativo de acordo com o desenvolvimento dos fetos, sendo nas fêmeas os valores maiores do que nos machos, pode-se observar um aumento evidente do comprimento entre os Grupos II e III, onde os fetos encontram-se na faixa etária de 40 e 50 dias, respectivamente. Os valores médios de cada grupo etário estão demonstrados na Quadro 1. 
Quadro 1. Valores médios do comprimento, espessura e largura do timo de cães, considerando sexo e faixa etária

\begin{tabular}{|c|c|c|c|c|}
\hline Grupo & & $\begin{array}{c}\text { Comprimento } \\
\text { (cm) }\end{array}$ & $\begin{array}{c}\text { Espessura } \\
(\mathrm{cm})\end{array}$ & $\begin{array}{l}\text { Largura } \\
(\mathrm{cm})\end{array}$ \\
\hline \multirow[t]{3}{*}{ I (Fetos 30 dias) } & Machos & 0,576 & 0,3575 & 0,4325 \\
\hline & Fêmeas & 0,67 & 0,445 & 0,55 \\
\hline & Média do grupo & 0,623 & $0,40125^{*}$ & 0,49125 \\
\hline \multirow[t]{3}{*}{ II (Fetos 40 dias) } & Machos & 0,83675 & 0,385 & 0,34975 \\
\hline & Fêmeas & 0,8775 & 0,4575 & 0,5075 \\
\hline & Média do grupo & 0,857125 & $0,426^{*}$ & 0,503 \\
\hline \multirow[t]{3}{*}{ III (Fetos 50 dias) } & Machos & 1,65375 & 0,4475 & 0,63 \\
\hline & Fêmeas & 1,913 & 0,4075 & 0,675 \\
\hline & Média do grupo & $1,7932^{*}$ & 0,419 & $0,652^{*}$ \\
\hline \multirow[t]{3}{*}{ IV (Fetos 60 dias) } & Machos & 2,3775 & 0,5275 & 0,965 \\
\hline & Fêmeas & 2,675 & 0,5675 & 1,0775 \\
\hline & Média do grupo & $2,522^{*}$ & 0,55 & $1,014^{*}$ \\
\hline
\end{tabular}

" Diferença estatisticamente significante $(p<0,05)$ se comparado o sexo.

Cada lobo tímico é revestido por uma cápsula delgada de tecido conjuntivo e pouca quantidade de tecido adiposo. Formam espessamentos em pontos de junção da cápsula com os vasos que nutrem o timo.
O tecido conjuntivo forma evaginações na cápsula, de onde partem numerosos septos que dividem parcialmente $o$ lobo formando a estrutura lobular. Nos pontos de emissão dos septos, predominam os vasos sanguíneos que principalmente nutrem o órgão que por sua vez se ramificam no percurso dos septos interlobulares e parênquima tímico.

Evidenciamos o epitélio subcapsular perivascular, que delimita toda a superfície e os espaços perivasculares do timo, apresentando-se achatado e alongado, formando uma divisão entre o espaço intratímico e o parênquima vascularizado.

Com o método "orientator", o órgão passou a ser isotrópico, assim não há como diferenciar a região cortical e medular nos cortes semi-finos.

A estrutura celular do órgão apresentou-se de forma organizada com a presença de agregados concêntricos, os corpúsculos de Hassal em todos os grupos estudados. $\mathrm{O}$ arranjo celular do Grupo II era semelhante aos do Grupo I, onde o timo apresentou-se de forma homogênea, as células do parênquima estavam próximas, no entanto eram menores, quando comparado com os animais do Grupo III e IV, porém, com vasos de calibre maior do que os animais do Grupo I. Não foram notadas diferenças visuais entre os machos e as fêmeas. Os animais do Grupo III as células distribuíram-se de forma difusa, os vasos aumentaram de calibre. Os animais do
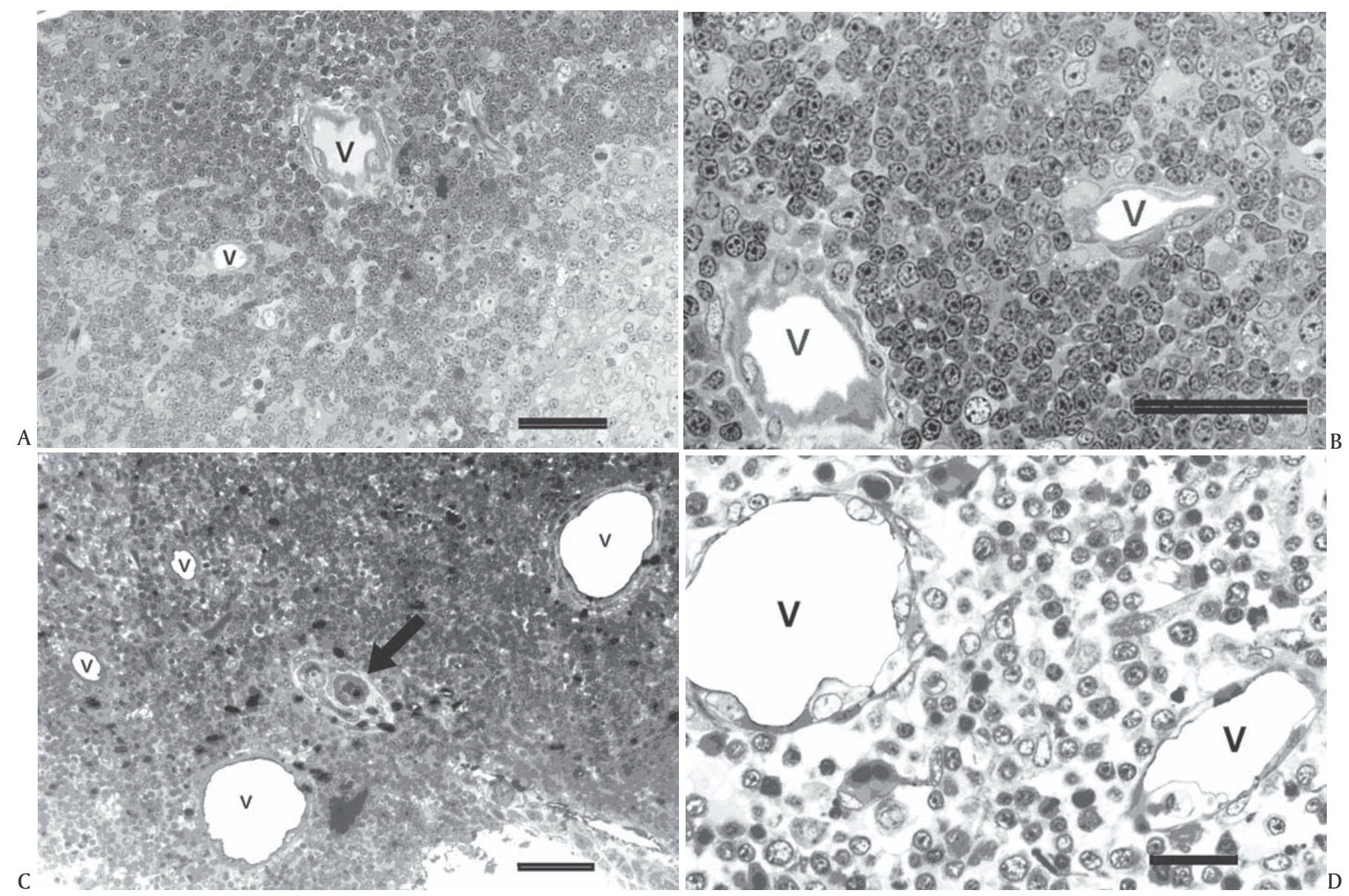

Fig.1. Histologia de timo de cães. A. Feto com 30 dias, macho (Barra $50 \mu \mathrm{m})$. B. Feto com 40 dias, macho (Barra $50 \mu \mathrm{m})$. C. Feto com 50 dias, macho (Barra 50 $\mu \mathrm{m}$ ). D. Recém-nato, 60 dias, macho (Barra $4 \mu \mathrm{m}$ ). Vasos (V), Corpúsculo de Hassal (seta). 
Grupo IV diferenciaram dos demais grupos por apresentarem vasos com maior diâmetro, sendo em maior número nos machos, as células apresentaram-se difusas e maiores. As células reticulares emitem fibras longas destacando um incremento na trama reticular no parênquima (Fig.1).

Houve diferença estatisticamente significante (Teste de Wilcoxon, $\mathrm{p}<0,05$ ) no comprimento do timo quando comparado os animais do Grupo II e III; na espessura quando comparado os animais do Grupo I e II, I e III, II e III

$\mathrm{O}$ volume do órgão ou volume referência (Vref) $-\mathrm{cm}^{3}$, foi estimado pelo método de Cavalieri através de planos macroscópicos paralelos e seriados, teve seus valores aumentados gradativamente de acordo com o desenvolvimento dos fetos, sendo maior nas fêmeas do que nos machos. Pode-se observar um aumento evidente entre os Grupos II e III. O volume referência variou em média no Grupo I de 0,1228 , sendo nos machos de 0,08906 e nas fềmeas de 0,16398 ; no Grupo II de 0,18366 , sendo nos machos de 0,11267 e nas fềmeas de 0,20374; no Grupo III de 2,06, sendo nos machos de 1,9125 e nas fêmeas de 2,175; no Grupo IV de 3,12, sendo nos machos de 3,11 e nas fêmeas de 3,24. Houve diferença estatisticamente significante (p $<0,05$ ) se comparado o sexo no Grupo III (Teste de MannWhitney), e quando comparado às faixas etárias entre os Grupos I e II, I e III, II e III (Teste de Wilcoxon). Nos demais grupos não houve diferença estatisticamente significante.

\section{DISCUSSÃO}

$\mathrm{O}$ interesse pela pesquisa do timo tem aumentado em virtude da importância que o tema vem assumindo e pela escassa literatura relativa ao órgão de maior importe do sistema imunitário dos animais. Dados relativos à vascularização arterial do timo em cães são incompletos, parcimoniosos e por vezes escassos.

Poucos autores estudaram anteriormente a histologia e a microvascularização especificamente do timo de cães, o que obrigou a considerarmos outras espécies de animais em nossas análises comparativas, respeitando as nuances que esta variável apresenta.

Nossos achados macroscópicos em cães foram semelhantes aos observados por Evans \& Christensen (1979) e Nickel et al. (1981) que descrevem o timo como um órgão de coloração rósea com discretas lobulações nos filhotes, localizado no espaço mediastínico cranial, entre os dois pulmões, e sua extremidade caudal é moldada na superfície cranial do pericárdio, apresenta apenas parte torácica, sendo esta dividida incompletamente em um largo lobo direito e um pequeno lobo esquerdo, seu pólo cranial se localiza abaixo da traquéia e estende-se além do primeiro par de costelas.

Junqueira \& Carneiro (1999) e Kato (1997) relatam que durante o desenvolvimento embriológico do timo, os vasos sanguíneos penetram no interior do parênquima acompanhando o tecido conjuntivo derivado da cápsula, formando espaços perivasculares ao redor dos vasos, fato este verificado também em nosso material. As vênulas da região medular confluem para formar veias que penetram nos septos conjuntivos e saem do timo pela cápsula do órgão. Já, as artérias penetram no timo pela cápsula, se ramificam, seguindo os septos conjuntivos onde originam arteríolas que penetram no parênquima seguindo os limites entre a cortical e a medular. Além disso, afirmam que o timo não possui vasos linfáticos aferentes, os poucos vasos linfáticos encontrados no timo são todos eferentes e localizam-se nas paredes dos vasos sanguíneos e no tecido conjuntivo dos septos e da cápsula do órgão, estes sofrem uma involução com o órgão, observações estas com as quais nossos resultados concordam.

Os achados macroscópicos quanto à irrigação do timo nos filhotes de cães estudados foram iguais aos observados por Evans \& Christensen (1979), Evans \& Delahunta (1980) e Silva et al. (1994) que afirmaram que o timo é irrigado por ramos das artérias torácicas internas, do tronco braquiocefálico, pericardicofrênica, troncos costocervical e primeira intercostal e artérias subclávias. Foi também observado a artéria torácica interna perfurando o tecido tímico como relatado por Schummer et al. (1981).

Venzke (1986) refere que a irrigação no cão procede de ramos das artérias torácicas interna e timopericárdica, um ramo que nem sempre está presente emitido do tronco braquiocefálico, e, na ausência deste vaso o timo recebe suprimento sanguíneo da artéria torácica interna esquerda, ramo este não encontrado por Evans \& Christensen (1979), Evans \& Delahunta (1980), Schummer et al. (1981), Silva et al. (1994) e em nosso estudo.

Concordamos com Silva et al. (1994) quanto à origem, que identificou modalidades de vascularização próprias para cada peça de fetos e natimortos de cães estudados.

Quanto à histologia do órgão concordamos com Didio (2002) e Firth (1977), os quais relatam que a cápsula e o septo do timo consistem de tecido conjuntivo areolar frouxo e tecido adiposo, formando espessamentos em pontos de junção da cápsula com os vasos que nutrem o timo.

Como os timos estudados foram isotropisados, não diferenciamos as regiões corticais, medulares e região transicional, a chamada junção córtico-medular, caracterizada por grande número de vasos, em geral arteríolas, circundadas por tecido conjuntivo perivascular, albergando linfócitos B e plasmócitos como relatado por Saint-Marie et al. (1986).

Como relatado por Dijkstra \& Sminia (1990), Picker \& Siegelman (1993) e Suster \& Rosai (1990) evidenciamos uma população de células tímicas imunofenotipicamente heterogenia em diferentes tamanhos, porém não diferenciamos as regiões corticais e medulares.

Como relatado por Dijkstra \& Sminia (1990) identificamos o epitélio subcapsular perivascular, que delimita toda a superfície e os espaços perivasculares do órgão, apresentandose achatado e alongado, funcionando, juntamente com as células endoteliais, macrófagos e linfócitos, como uma divisão entre o espaço intratímico e o mesênquima vascularizado, considerado como o substrato morfológico da barreira timosangue, porém, Nieuwenhuis et al. (1988) discorda com o trânsito antigênico transcapsular.

Como relatado por Henry (1992) e Nabarra \& Adrianarison (1995) os corpúsculos de Hassal foram evidenciados em todas as faixas etárias estudadas como uma estrutura tubular complexa. 
O método de Cavalieri e o coeficiente de erro usado para obtenção do volume do órgão também foram utilizados nos trabalhos de Duerstock et al. (2003), Gundersen \& Jensen (1987), Mayhew (1992) e Wulfsohn et al. (2004), assim como o fizemos.

O volume do timo aumenta com o desenvolvimento do animal, tendo um aumento brusco no Grupo IV (recém-natos com 60 dias), acredita-se que esse aumento deve-se ao fato de que ao nascimento o órgão apresenta-se totalmente desenvolvido para exercer sua função linfopoiética, conforme indicação contida na literatura, estabelecendo-se após a maturidade sexual sua involução (Drummond 1996, Bombonato 1997).

Com a proximidade do nascimento, acredita-se, conforme indicado na literatura, que ocorram alterações mediadas por hormônios de fatores angiogênicos provocando um aumento não somente no número e densidade vascular, como também no tamanho dos vasos nos recém-natos com 60 dias (Grupo IV).

\section{CONCLUSÕES}

O timo apresentou-se composto por dois lobos unidos por um tecido de conexão, com coloração rósea, localizados no espaço mediastinal cranial, entre os pulmões e acima da base do coração, sua porção cranial estendeu-se pouco além do primeiro par de costelas.

A estrutura celular do timo mostrou-se organizada com a presença de agregados concêntricos, os corpúsculos de Hassal, envolvidos por uma delgada cápsula de tecido conjuntivo que é espessada por tecido adiposo, servindo de substrato para a passagem dos vasos sanguíneos, dispondo-se em arquitetura lobular.

Os vasos observados na microscopia de luz de cortes semifinos, aumentaram de tamanho gradativamente de acordo com a idade, sendo mais evidente nos animais do Grupo IV (60 dias), próximo ao nascimento.

Os timos, das fêmeas, apresentaram maior volume (Vref) e dimensões de tamanho que nos machos. Em ambos os sexos foi observado um evidente aumento no volume e comprimento do timo entre os Grupos GII e GIII, ou seja entre a faixa etária de 40 e 50 dias.

\section{REFERÊNCIAS}

Appolinário A.V.M. 1998. Vascularização arterial do timo de coelhos (Oryctolagus cuniculus, Linnaeus, 1758) da raça Nova Zelândia Branco. Dissertação de Mestrado, Faculdade de Medicina Veterinária e Zootecnia, Universidade de São Paulo, São Paulo. 66p.

Banks J.W. 1991. Histologia Veterinária Aplicada. $2^{\underline{a}}$ ed. Editora Manole, São Paulo, p.370-390.

Bombonato P.P. 1997. Aspectos da morfologia, topografia e vascularização arterial do timo em fetos de búfalo. Tese de Livre Docência, Faculdade de Medicina Veterinária e Zootecnia, Universidade de São Paulo, São Paulo. 88p.

Didio J. 2002. Tratado de Anatomia Sistêmica Aplicada. $2^{\underline{a}}$ ed. Atheneu, São Paulo. 488p.
Dijkstra C.D. \& Sminia T. 1990. Hemopoietic System. Springer Verlag, Berlin, p.185-193.

Drummond S.S. 1996. Aspectos morfométricos e vascularização arterial do timo em suínos da raça Hampshire. Tese de Doutorado, Faculdade de Medicina Veterinária e Zootecnia, Universidade de São Paulo, São Paulo. 57p.

Duerstock B.S., Bajaj C.L. \& Borgens R.B.A. 2003. A comparative study of the quantitative accuracy of tree-dimensional reconstructions of spinal cord from serial histological sections. J. Microscopy 210:138-148.

Evans H.E. \& Christensen G.C. 1979. Miller's Anatomy of the Dog. 2nd ed. W.B. Saunders, Philadelphia, p.839-840.

Evans H.E. \& Delahunta A. 1980. Miller's Guide to the Dissection of the Dog. 2nd ed. W.B. Saunders, Philadelphia, p.115-122.

Firth G.A. 1977. The normal lymphatic system of the domestic fowl. Vet. Bull. 47:167-179.

Gundersen H. \& Jensen E. 1987. The efficiency of systematic sampling in stereology and its prediction. J. Microscopy 147:219-223.

Henry K. 1992. Thymus, Lymph Nodes, Spleen and Lymphatics. Churchill Livingstone, Edinburgh, p.27-139.

Junqueira L.C. \& Carneiro J. 1999. Histologia Básica. Guanabara Koogan, Rio de Janeiro, p.220-240.

Kato S. 1997. Thymic microvascular system. Microsc. Res. Techn. 38:287299.

Machado G.V. 1989. Sobre a origem, o número e a esqueletopia dos ramos arteriais destinados ao timo, em fetos de eqüinos SRD (Equus cabalus). Tese de Doutorado, Faculdade de Medicina Veterinária e Zootecnia, Universidade de São Paulo, São Paulo. 30p.

Mattfeldt T., Mall G., Gharehbaghi H. \& Moller P. 1990. Estimation of surface area and length with the orientator. J. Microscopy 159:301-317.

Mayhew T.M. 1992. A review of recent advances in stereology for quantifying neural structure. J. Neurocytol. 21:313-328.

Nabarra B. \& Andrianarison I. 1995. Thymic reticulum of mice. III. The connective compartment, innervation, vascularisation, fibrous tissues and myoid cells. Tissue and Cell 27:249-261.

Nickel R., Schummer A. \& Seiferle E. 1981. The Anatomy of the Domestic Animals. Paul Parey, Berlin, p.269- 440.

Nieuwenhuis P., Stet R.J., Wagenaar J.B., Wubbena A.S., Kampinga J. \& Karrenbeld A. 1988. The transcapsular route: a new way for (self-) antigens to bypass the blood-thymus barrier? Immunol. Today 9:372.

Picker L.J. \& Siegelman M.H. 1993. Fundamental Immunology. 3rd ed. Raven Press, New York, p.43-44.

Sainte-Marie G., Peng F.S. \& Marcoux D. 1986. The stroma of the thymus of the rat: morphology and antigen diffusion, a reconsideration. Am. J. Anatomy 177:333-352.

Schummer A., Wilkens H., Vollmerhaus B. \& Habermehl K.H. 1981. The Anatomy of the Domestic Animals. Paul Parey, Berlin, p.283-288.

Seto F. 1981. Early development of the avian immune system. Poultry Sci. 60:181-195.

Silva F.O.C., Bombonato P.P., Severino R.S., Drummond S.S., Santos A.L.Q. \& Borges M. 1994. Suprimento arterial do timo em cães SRD. Braz. J. Vet. Res. Anim. Sci. 31:89-94.

Suster S. \& Rosai J. 1990. Histology of the normal thymus. Am. J. Surg. Pathol. 14:284-303.

Venzke W G. 1986. Sisson/Grossman Anatomia dos Animais Domésticos. $5^{\underline{a}}$ ed. Guanabara Koogan, Rio de Janeiro, p.163-167.

Wulfsohn D., Gundersen H.J., Vedel Jensen E.B. \& Nyengaard J.R. 2004. Volume estimation from projections. J. Microscopy 215:111-120. 